\title{
The Hierarchy of Values in the Contemporary Science
}

\author{
Iurii A. Mielkov ${ }^{1}$ \\ ${ }^{1}$ Interregional Academy of Personnel Management, Kiev, Ukraine \\ Correspondence: Iurii A. Mielkov, Interregional Academy of Personnel Management, Kiev, 03039, Ukraine. Tel: \\ 380-68-351-0973. E-mail:ym173@ya.ru
}

Received: February 28, 2016

Accepted: March 23, 2016

Online Published: March 31, 2016

doi:10.5539/res.v8n2p149

URL: http://dx.doi.org/10.5539/res.v8n2p149

\begin{abstract}
The author follows the philosophical conception of the contemporary science that presents it as "post-non-classical" - as an emerging paradigm of dialectical comprehension of scientific knowledge that resolves the contradiction between classical monism and non-classical plurality by enabling the approach to considering the reality as unity in plurality. In the light of that conception, scientific values and goals constitute an elaborate hierarchical system, its highest level being presented by the ideal as the embodiment of both the final goal of the whole activity and the fundamental value that defines the goal-setting on lower hierarchy levels. The current crisis of science, as well as crises visible in many other spheres of human activity, could in fact be traced to the crisis of values - particularly, to the latency of the higher levels of values, and especially that of the ideal, that forces lower "means" to serve as quasi-values while profaning the whole enterprise. That is, instead of searching for the truth, scientific community is engaged only in mundane activities like supporting its own institutional existence and providing profit for its members. The proposed solution to the current crisis could be presented in the form of asserting human personality as the autonomous subject of moral judgment and philosophical recognition of the ideal level as the ultimate determinant of scientific activity.
\end{abstract}

Keywords: hierarchy of values, post-non-classical science, objectivity, human dimension of science

\section{Introduction}

The problem of values remains one of the most popular topics for the research conducted today in the field of philosophy of science and humanities. Comprehending axiological and ethical aspects of scientific knowledge becomes now more and more urgent as the classical science with its "value-free" attitude is now considered to have been one of the major factors for the emergence of the current ecological crisis and the general crisis of humankind civilization in its relation to the natural world. The dichotomy of science and values that had once determined our vision of scientific knowledge is now being disputed, if not rejected (Putnam, 2002), axiological aspect of the whole scientific enterprise now being considered as its integral part, with present-day scientific practices demonstrating their new value-ridden features.

Such statements are justified by the fact that science now recognizes two types of values that inherently influence both the process and the results of scientific knowledge. The first type is namely the values peculiar to science, like the truth as the regulative norm of scientific knowledge. The second type is more difficult to denote as it relates to the values that trace their origins to other fields of human cultural activity, like philosophy, the arts, or even religion. Indeed, as the said ecological threat finds its recognition among scientists themselves, it turns out that the very existence of nature (as the object of scientific studies in general) and the very existence of humankind is the intrinsic value of all human culture, including science per se. That means that axiological factors now tend to be incorporated into the very body of scientific knowledge: on the one hand, as factors that denote some restrictions as for the freedom of scientific enterprise (like limiting the possibilities of experiments), and on the other hand, as forms of human attitude towards the objects of his or her study. The manifestation of the later phenomenon could be demonstrated on the example of such notion as biophilia - as Edward has argued, it is a kind of unindifferent attitude of the cognizing human being toward the living world as the object of his or her biological studies (Wilson, 1993).

Of course, such attitude is in no way limited to biology. In other words, major topic for philosophical consideration of the contemporary science is the analysis of its inherent values, classification of such values, and research of their statuses in relation to the human as the cognizing subject. The reason for that task to be of 
urgent nature for the contemporary science is the difficulty that describes that task of finding the relation between the two types of science, or, to put it in more general way, the relation between objectivity of science and values of science. The authors dealing with this issue come to opposite conclusion, from postulating "ethics without ontology", i.e., the possibility of values without any hint of objectivity (Putnam, 2005), - to repeating classical visions of the objectivity as the notion completely rid of any evaluation and even of any interpretation (Daston \& Galison, 2010). However, the two opposite approaches denoted, like those extreme points of opposing unity and plurality, do not help much in determining the actual role and meaning of values in the course of scientific activity. And that's the task I will to try to find the possbile approaches to carrying out in the proposed paper.

\section{Materials and Methods}

Axiological aspects have started to emerge as a separate part of philosophical studies since 1920s. While at first they tended to include only humanities, in accordance with the ideas of Neo-Kantianism and Existentialism that viewed values as something not peculiar to (the classical) science, already in 1940s Robert had formulated the structure of "the ethos of science" (Merton, 1973).

The topic of the relation between science and values was becoming increasingly popular in philosophy of science since 1960s and 1970s both in USA and Europe, as well as in the USSR (where philosophy of science was always one of the most popular and fast-growing field of studies because of it being relatively free from the ideology of the Communist party). The idea that the values that determine human activity could be different as of their importance and relevance, that is, that they actually could be shaped out as a certain hierarchy, also starts to be evident in those times. Thus, North American philosopher and ethicist Abraham Edel argued in 1960s that there are two quite different type of morals: the first one answers the question "what would our conscience say", while the second one is more concerned with "what would help us to preserve our community" (Edel, 1963, p. 209). That idea did not find much development then, but now it could be considered as some background for social ethics and for the philosophical comprehension of values in general.

At the same time, philosophical studies of similar themes conducted during the same historical period in the former Soviet countries is little known to English-speaking readers, while the investigations of scientific knowledge within the scope of its relation to human values and human activity carried out particularly by representatives of Kiev philosophy school of the 20th c. could present a lot of interest for consideration of similar topics in relation to the present-day scientific practices. That's why I refer to the works by Ukrainian philosophers of the past century-Pavel Kopnin (Kopnin, 1973), Vladimir Shinkaruk (Shinkaruk, 2003), Alexander Yatsenko (Yatsenko, 1977), Sergey Krymskiy (Krymskiy, 2012) and other their colleagues - as a methodological base while researching the relation between science and values.

Finally, one of the most elaborate philosophical conceptions of the contemporary science is the one proposed by Russian philosopher Vyacheslav Stepin in his theory of post-non-classical science (see Stepin, 2005) that develops Thomas Kuhn's notion of scientific revolutions and scientific paradigms. According to Stepin, currently we experience the fourth global scientific revolution leading to the formation of the new type of scientific rationality the features introduction of human cultural values into the very core of scientific knowledge as science turns its attention toward complex objects that are found to be "human-commensurable" (Mielkov, 2013). Considering that feature to be the important determinant of the present-day scientific paradigm serving as philosophical foundation for interdisciplinary scientific practices, I would refer to those practices as post-non-classical ones meaning their relation to values that does not correspond to that of the "value-free" ideals of classical science from the past.

\section{Results}

\subsection{The Notion of Value, and How the Hierarchical Approach Could Help Us to Define It More Precisely}

First of all, before trying to investigate values of the present-day science from philosophical point of view, it would be wise to start from defining the nature of the very notion of "value". As I have already noted, investigations of values in philosophy have been triggered by the birth of axiology as a specific discipline of philosophical knowledge. The development of that discipline in the 20th c. has led to the idea that under the perspective of axiology, as argued by Valerii Zahorodniuk, "all phenomena of the human world are themselves certain goals and values that should correlate to 'the highest predestination' of the human being" (Zahorodniuk, 1991, p. 7). However, I think that such a description rather complicates the definition of the notion of "value" than clarifies its meaning - and its relation to the notion of "goal" as well. In fact, it is "the highest predestination" that could be described as both value and goal in the true sense, while all other things are endowed with qualities of being goals and values only to the extent of their correlation with "the highest 
predestination" in question.

In other words, they are not actual values in the proper sense but rather relative values - and it would be more appropriate to denote them as means for reaching the highest goal, and not actually goals themselves as a goal is something we want to achieve because of its intrinsic value and not because of the possibility to use it in order to get something else. As Kazakh philosopher Aliya Abisheva says, axiology in this sense is nothing else than pointless and fruitless "re-registration" of all things as values (Abisheva, 2002), while only "the highest predestination" and the ultimate goal is in fact the value - that enables all other things to be valuable as well. A goal then is value in itself, and a value is an ultimate goal of human activity because of its appeal to us.

\subsection{The Hierarchy of Values}

I think that the denoted contradiction between the two meanings of the notion of "value", as the highest goal in itself and as a denotation for a number of phenomena perceived as valuable because of their relation to that goal - that contradiction could well serve as a driving force for the further philosophical comprehension of values. That is, values are different and non-equivalent to each other; they form a certain hierarchy, and researching that hierarchy could be excellent way to classify the present multitude of value phenomena without going back to the classical monism with its aversion to any kind of alternative. Let's refer to the old example used in Medieval logic studies - that of the three construction workers from the city of Chartres. When asked what are they doing, the first one said he carries bricks, the second one explained he is earning his living, and the third one answered he is building the cathedral. These are tree types of activity - and three goals. They are different on the first sight, but thoughtful consideration enables setting up a certain hierarchy out of those goals. The task "to carry a load of heavy bricks from point A to point B" could well serve as means for achieving some other goal and for realizing some other values - like, say, execution of the superior's command or a way to earn one's living and to support one's family - up to the more global task of building the famous cathedral of Chartres. Thus, the three goals of the three construction workers form a hierarchical structure: from elementary goal to the most substantial and generally valid.

In contemporary philosophy, an elaborated hierarchy of goals and values is proposed by American philosopher of German heritage Nicholas Rescher. He chooses medical practice as his example, where the ultimate goal (and the first highest level of hierarchy) turns out to be the final result of the said practice - that is, "health". The second level features the leading principle or the regulative idea for the practical activity - namely, some strategy for curing the illness that has been diagnosed. The next level is denoted as "tactics" and includes more particular norms, standards and criteria that define certain the symptoms for the illness and rules for getting rid of those symptoms. The fourth level is constituted by goals and rules for conducting specific procedures, like operation surgeries. Finally, the lowest fifth level is the level of instructions, what Rescher calls rational and guaranteed prescriptions, like particular instruction for a patient to take a certain number of pills at a certain time (see Rescher, 2004, pp. 29-32).

Introduction of such hierarchical approach to comprehending goals and values enables us to conduct even some dialectical distinction between the absolute and the relative in ethics-Rescher even compares the proposed approach to the "hierarchy of truths" in Catholic theology (Rescher, 1997, pp. 141-144). That is, morality is found to be absolute and universal for all rational actors on the level of basic principles, but it is possible (and even necessary) to specify those principles and to define them more concretely according to contexts of different social communities on lower levels. We can't thus follow the relativists in stating the existence of several distinct types of human morality while not denying the very nature of morality itself as something universal and generally valid. Different persons and different communities are free to agree or disagree on some more concrete levels of defining goals and values, but in order to do that they have to share some common goals and values - including those that make their agreement or disagreement possible at all. For example, we can argue on how to solve ecological crisis, or how to improve the quality of human life in different countries of the world - but the background for our very argument is set up by the common goal of "preserving human life" and "preserving nature", the existence of human life and the existence of nature constituting here our universal values regardless on our disagreement on the means for achieving them.

\subsection{Ideals as the Highest Form of Values}

Considering human values as a certain hierarchy enables us to conduct more precise philosophical distinction of goals and means as well, the only actual goal being that of the highest level, like "health of the patient" for medical practice (and not the profit earned from that practice by a doctor) as some ultimate foundation and motive for human activity. In fact, it is one of the best available definitions for philosophy itself, considering it to be a reflection of ultimate universal foundations. According to Kiev school of philosophy, such a foundation is 
better called the ideals. As defined by Alexander Yatsenko (Yatsenko, 1977, p. 153):

"Ideal is the mental specimen of perfection, the norm we should strive for as the final goal of an activity. That's why it determines the direction, the manner and the nature of the behavior of the subject who follows it. In different spheres of human existence, there are notions of supreme perfection being shaped out, that perfection serving as a specimen and the ultimate guideline for the activity".

It is worth noting that such understanding of ideal differs from its classical Kantian comprehension as something knowingly unattainable. But the contemporary realist philosophy as explained by Pavel Kopnin (Kopnin, 1973), considers ideal to be an immanent process, a development towards its own approximation and realization - and still a process of its own constant renovation and clarification. Each stage of the process in question is gradual but goal-seeking embodiment of the ideal—while the latter remains purely theoretical and mental, it still serves as an object for full sensual comprehension, so that human person who value that ideal and strives for it is willing to apply all his or her energy in order to achieve some approximation to the ideal.

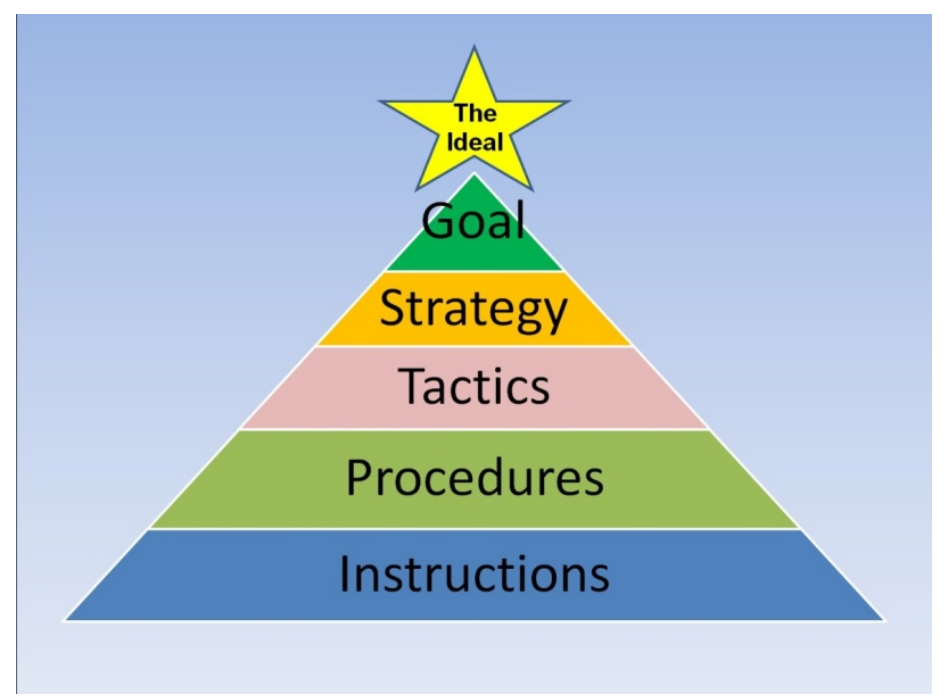

Figure 1. A hierarchy of goals and values in human activity

At that, the interrelation between goals that present a form of the desirable result of some practical activity and values that answer not the question "what?" but the question "why?", as noted by Vyacheslav Stepin (Stepin, 2011) is not that of identity. A value determines a whole set of optional goals that we can set for ourselves in accordance with our affinity to that kind of values. And that distinction only accentuates the necessity to comprehend goals and values by positioning them in a hierarchical manner: the first stage in the proposed hierarchy, the ideal, is at the same time the highest (i.e., the most universal) value and the ultimate goal to be realized - the final mental determinant of human activity able to define more particular goals and values.

Other levels of constituting goals serve as means for achieving the ideal as the unity of goal and value, while in relation to even more particular levels they themselves form a goal-setting value. That is, "strategy" of the second level of the hierarchy forms the goal for "tactics" while being itself means for the "ultimate goal" of the first level, and so on (see Figure 1). Getting back to the dialectics of the absolute and the relative and trying to summarize the ideas expressed in this paragraph of the paper - it is possible to make a conclusion that basing on the hierarchical comprehension of goals and values, all disagreements currently existing in the world in relation to such complex phenomena could be indeed solved by the ascension to higher levels of goal-setting that, in turn, characterize higher, broader, and more universal layers of personal identities of human being as the subject of axiological judgment.

\section{Discussion}

To discuss the proposed approach to considering the values of the contemporary science in a hierarchy, let's get back to the main topic of our investigation, namely to the consideration of the contemporary science and post-non-classical situation of knowledge that is aptly interpreted in terms of unavoidable interrelationship of knowledge and the subject of knowledge. In non-classical science that corresponds (in Stepin's conception) to the theories of quantum mechanics and relativity in the 20th century physics, the result of the knowledge was 
determined by the means of cognition forcing the scientist to introduce "a correction" related to the device situation and to take into account the chosen reference point. Under the present-day situation, science reveals even more precise forms of the dependence of knowledge from the cognizing subject - and that leads to a necessity of clarifying the position and many other qualities of that subject, answering another question: "who?", as denoted by Iryna Dobronravova. For example, if we try investigating a situation of ethnic conflicts like those that take place in post-Soviet states since the end of 1980s, then we should definitely take into account the personality of a witness describing the conflicts we intend to study. That is, a description of the conflict between Armenians and Azerbaijanis, the Nagorno-Karabakh War, could be described quite differently by an Armenian witness and by an Azerbaijani witness (Dobronravova, 2009).

\subsection{Relativism and the Social Dimension of Science}

One could wonder if such a feature leads to the questioning of the nature of the science itself with its strife towards objective knowledge, or if there are two "sciences" emerged in correspondence to the two opposite positions - and not only two of course but as many as possible according to the number of actual witnesses and potential subjects of knowledge. However, the threat of such extreme relativism where there is not the common science but a number of sciences, like "a science of John" and "a science of Peter", is but an exaggeration that has little to do with actual scientific practices. The major attribute of the contemporary situation could be best described by the transfer of the right to be the subject of knowledge and the subject of value-setting to one or another community, as opposed to both personalistic (humanist) approach and the universal (humankind) tradition of the past that is now considered to be rather abstract and too remote from everyday life. There are many trends emerging today in the field of social philosophy emphasizing just the need to take into account that "middle level" of communities that had been neglected by classical theories engaged in studies of the society in general or human persons in particular (see Boychenko, 2011). There is no doubt that that level is indeed important, but considering its role in goal-setting as the absolute one could still lead to the threat of relativism in comprehending values. Say, it is this approach that has contributed to the formation of such dubious forms of scientific ideology in the 20th c. as "class science", "race science", "national science", or "gender science"- that is, postulating the existence (or the necessity of creation) of some specific, private science as opposed to the universal common science per se.

In spite of all possible positive consequences that could spring from such a proliferation of human identities, scientific partisanship remains an ill-reputed notion because of its open proclamation of the priority of particular, group interests in contrast to the objective truth that is - as the ideal of scientific knowledge - one and universal by its very definition. Social dimension of science does not mean the affirmation of values that enrich the science-instead, the scientific activity itself could be considered as means for achieving some particular ends instead of the truth. A good example of such relativist approach is the article by Helen Longino titled "How Values Can Be Good for Science" - where the science is literally considered on the base of its usefulness to the realization of non-scientific values related to, say, gender (Longino, 2004).

In the contemporary philosophy, there is no methodological or moral justification to assert that the only alternative to the classical monism (with its uniform system of values and its single truth perceived at times as "authoritarian" or even "totalitarian") is just the non-classic (or, post-modern) relativist plurality that not only denies the existence of any actual unity concerning scientific knowledge but imposes tacit ban on any search for such a unity in its potentiality and its future perspectives of the becoming. That's what could be called "collective solipsism" or "Fichtean intersubjectivity"- and I think it is not a decent and effective substitute for a classical objective truth however incomplete and erroneous the correspondent theory of the objective truth could be estimated to be.

\subsection{A Unity in Plurality as A Way to Comprehend Values}

Of course, considering the dialectical nature of the very notion of "post-non-classical" science, it is not difficult to come to a conclusion that it is "unity in plurality" that serves as a guideline for the proposed approach to perceive the values of science. That does not mean coming back to the classical unitary vision: overcoming the dichotomy of unity and plurality does not deny the plurality - it denies just the equivalence of all possible reference points. And that's where the hierarchical approach comes to help by not reducing plurality to the unity but by defining the structure of the plural positions in order to overcome the threat of relativism. As explained by Nicholas Rescher:

"The fatal flow of such radical relativism lies in its failure to distinguish sufficiently clearly between matters of custom and social approval on the one hand and matters of principle and moral propriety on the other" (Rescher, 1997, p. 145). 
In other words, the strict pluralist approach lacks the ability to distinguish between universal morality and particular morality, between norms and goals of higher level and those of lower levels of relevance. And that's why the relativist approach is ineffective for contemporary philosophical consideration of human activity in general and scientific knowledge in particular. In fact, the ineffectiveness in question could be defined as a drawback of many present-day practices when the very existence of higher-level values that could present ultimate determination for our goal-setting is not revealed and appears to hidden from our sight by more particular and mundane goals and values.

A human-commensurable system, in spite of all its value-ridden nature and complexity, could lose the sense of its existence and activity if that activity is not correlated to some higher values. The leader of St-Petersburg school of synergetic and philosophy of science Vladimir Branskiy even introduces the term "super-attractor" in order to denote some higher level of system's values - the one that could not actually emerge as a result of self-organization but in turn enables the very process of self-organization as a whole (Branskiy, 2012). At that, super-attractor is in no way a single and immutable "quasi-classical" and "totalitarian" unitary value that predefines everything - it does not describe the ways to achieve the ideal, but it clarifies the sense of its approximation. Ideal nature of the highest value sets up the ground for multiple activities realizing that value, so that none of programs of the realization in question (strategy, tactics, procedure and so on) could be conceived as pre-defined and immutable. Thus, the plurality of means (and the plurality of concrete subjects using that means, and the plurality of concrete circumstances for carrying out the different forms of activities) is enabled by the universality of the highest goal and value (and not suppressed by it).

Following the ideal — and not just programs or procedures - allows us to replace those procedures, and tactics and even strategy, if, say, the proposed methodology for curing an illness would be found to be ineffective. In that case, it means that the highest goal (the patient's health) is the common highest value for both the patient (in order for him or her to follow basic prescriptions and instructions) and the doctor (for whom that value should be more important than the prestige or the tradition of his clinic, or the profit obtained from the patient). Only then the doctor would have enough motives and determination to change the erroneous strategy or tactics in curing the illness.

\subsection{Human Reality in the Hierarchy of the Points of View}

That approach is relevant for any type of human activity. Namely, as Spanish philosopher Jose Ortega y Gasset stated earlier in the 20th century while referring to phenomenological perspectives of cognition, one and the same reality could be "split up into many diverse realities when it is beheld from different points of view. And we cannot help asking ourselves: which of all these multiple realities is the real and authentic one? Any decision we make cannot but be arbitrary" (Ortega y Gasset, 2007, pp. 54-55).

It is important to note that the Spanish philosopher has proposed himself a certain workaround to making non-arbitrary decisions in such cases where the multitude of "perspectives", or the plurality of points of view, hinders achieving the classical monist truth, while relativism still remains out of question in scientific investigations. Particularly, the perspectives in question always form a hierarchy-as each of them finds itself in a certain relation towards the object being observed or the event taking place. For example, if we picture an event of death of some famous man, says Ortega, all different persons gathered around him, like his wife, his doctor, some friends, a reporter and maybe several casual observers - their positions are not are not all of the same standing. That is, the wife is the closest person to dying man, while a chance observer is the most distant one. So, if an artist would happen to be there as well in order to capture the historical event for the posterity, he is to picture "the higher reality", the closest perspective, in order to be able to express live emotions:

Quiere decir esto que en la escala de las realidades corresponde a la realidad vivida una peculiar primacía que nos obliga a considerarla como "la" realidad por excelencia. En vez de realidad vivida, podíamos decir realidad humana. El pintor que presencia impasible la escena de agonía parece "inhumano". Digamos, pues, que el punto de vista humano es aquél en que "vivimos" las situaciones, las personas, las cosas. Y, viceversa, son humanas todas las realidades - mujer, paisaje, peripecia — cuando ofrecen el aspecto bajo el cual suelen ser vividas (Ortega y Gasset, 2007, p. 57).

("That means that in the scale of realities, a certain primacy is given to the 'living' reality so that we are obliged to consider it being 'the' reality par excellence. Instead of a living reality, we could talk about 'human' reality. An artist who impassively observes the scene of death appears as 'inhumane'. Let us say then that 'human' point of view is the one in which we 'live' situations, persons, or things. And, vice versa, any realities are humanized - a woman, a landscape, a fibula — when they are presented in the aspect that enables them to be 'living,.") 
In fact, the proposed approach makes sense for every possible human practice. The existence of "a living" reality is not an absolute thing as it changes with every event in question-but it does exist as something enabling the ground for any possible perspective.

Particularly, in the case when the hierarchy of values is not being followed, we can have certain forms of dysfunctions and crises, and even a profound crisis of purpose in contemporary science. The latter is in fact a reflection of the crisis of the goal-setting and the crisis of the ideals. If the science loses its orientation on the search for the truth as its ultimate goal and the truth itself as its highest value and as an epistemological ideal available for approximation - then the science has only its functioning as a social institute as its empiric goal, like conducting formal research and obtaining degrees without any correlation of that activity with higher external values - like carrying a heavy load of bricks from one point to another in order to earn for a living and totally without thinking about building a cathedral. Thus, the science loses its universal appeal —and its true sense of existence, even if it is still being widely used by commercial enterprises as a source of effective technological products.

\subsection{Ethos and Morality in Scientific Activity}

Let us remind the major points of "the ethos of science" formulated by Robert K. Merton in 1942: the four institutional imperatives of science, according to the founder of sociology of science, are universalism (as independence of scientific knowledge from all particular interests, like that of "national science" imitation created in Nazi Germany), communalism (as free transfer of the results of a scientist's activity to common usage), disinterestedness (unselfishness of scientific activity supposing no other goals for a scientist than the search for the truth) and "organized skepticism" as both institutional and methodological orientation on critical consideration of any object (see Merton, 1973, pp. 271-273).

Robert Merton has repeatedly emphasized that he was investigating and enunciating institutional ethical values for science and not personal or motivational-however, his imperatives could be rather related to the ideal norms and not to actual ethos, i.e., to the existing habits and customs. Merton's numerous critics have essentially noted just the discrepancy between those definitions and the real scientific practices, especially taking into account their historical dynamics and local specifics. For instance, present-day Russian philosophers dealing with the ethos of science acknowledge Merton's formulas to be the classical example of norms proclaimed and not executed - and even conclude that in the situation of free-market economy at least the imperative of disinterestedness is no longer valid (see Mirskaya, 2008).

I have to clarify though that imperatives, norms and even more so the ideals are not to be evaluated basing on their empirical embodiment in one or another scientific community or by local specifics of their distribution. It is how morality as the unconditional maxima differs from ethos as a number of actual habits: even if there is only one single person (or, select few of them) among scientific community who follows the moral imperatives of science, those imperatives are still the measure and the specimen of science - in difference from other habits that could be well wide-spread but still not reflecting the ideals of science per se. In other words, that's what "human-dimensionality" of the contemporary post-non-classical science means: the morality of science (its values and its "ethos" in Merton's term) could be only based on the responsibility of human personality as the autonomous subject of morality and goal-setting (see Mielkov, 2014).

There is an excellent example of such situation in the present-day science-the case of Grigori Perelman, Russian mathematician who solved the Poincaré conjecture while turning down any awards and prizes for such an accomplishment - and just as a gesture of disapproval for the customs and habits of contemporary scientific community. Sylvia Nasar and David Gruber in their already famous New Yorker article give a rare testimony of Perelman himself who explains his decision in the following way: "It is not people who break ethical standards who are regarded as aliens," he said. "It is people like me who are isolated." [...] Of course, there are many mathematicians who are more or less honest. But almost all of them are conformists. They are more or less honest, but they tolerate those who are not honest. (Nasar \& Gruber, 2006, p. 57). And, as Mikhail Gromov, the Russian geometer and once a tutor of Perelman, explains his words:

"To do great work, you have to have a pure mind. You can think only about the mathematics. Everything else is human weakness. Accepting prizes is showing weakness." [...] "The ideal scientist does science and cares about nothing else," he said. "He [Grigori Perelman] wants to live this ideal. Now, I don't think he really lives on this ideal plane. But he wants to." (Nasar \& Gruber, 2006, p. 57).

\subsection{Conflicts and Dysfunctions as Results of Substituting Ends with Means}

This situation well illustrates the appropriateness of the hierarchical approach to values of science: following the 
truth brings you scientific discoveries first, and not awards and recognition - the latter could come as a (wanted or unwanted) supplement to the truth. While setting up only awards and recognition as (the only) goal for scientific activity could bring them - but not the discoveries.

So much the worse for science if it does not correspond to its notion, as Hegel would say- that is, its ideal form. That is, science is what Perelman and other "idealists" do and follow-rather than what other $99 \%$ of the members of scientific community do and follow. The reason for the possible crises in science and in all other areas of human activity is thus the latency of the higher levels of values, and especially that of the ideal, that forces lower "means" to serve as quasi-values while profaning the whole enterprise.

One example of such a situation in social sciences could be presented by the situation of "multiculturalism": the plurality of cultures in the present-day world (see Bakhov, 2013; Bakhov, 2014) makes any sense only if it is based on the idea of some psychic unity of the humankind providing the ground for the dialogue (and even the meaningful argument) of different cultures-I would say that they have to have something in common in order to be different. The problems (and conflicts) come when there is no higher level of values available for consideration, as then means (or, goals of the lower level) take the place of ends and values. That means that the system finds the only sense of its own existence-in supporting that very existence. It functions in order to function, and not in order to achieve anything external (and thus valid outside the system in question).

That's what best describes the age of stagnation-like that in the late Soviet years that were aptly described by Vladimir Shinkaruk as "ideology without the ideals" (Shinkaruk, 2003, p. 292). "Ideology" here as a system of ideas called to concretize and to reveal the higher ideals by setting goals for their actual achievement (and in this case it is the ideal of the optimal social, economical and political organization of the humankind) - that system is locked in itself, transforms itself into a set of empty dogmas nobody believes into as they lack any substantiation and are only obeyed due to some sort of mechanical inertia as ritual incantation that have no real power and do not represent "a living reality".

Of course, it would be too pessimistic to call our whole contemporary situation in science and in culture the stagnation that features conflicts and dysfunctions. However, there are many reasons to believe the threat of relativism in values is immanent, and the crisis of science is a reality. As for the ways to solve it - I can only argue that the hierarchical nature of values and goals is to be considered as a justified topic of philosophical consideration of the contemporary science, and the human dimension of that science would become the source of knowledge of the necessity for each human person to serve as the subject of goal-setting and the subject of value recognition, as only then the universality of cultural values would enable the plurality of other values related to social communities and other groups without denying their existence and without substituting means for ends.

\section{Conclusion}

Philosophical consideration of the goals and values for human activity carried out from the position of post-non-classical paradigm of scientific knowledge enables us to evaluate the system of such goals and values as a hierarchy. The highest level of the latter is constituted by ideals that are at the same time embodiments and ultimate goals for the whole activity, and basic values defining the features of goal-setting process at lower levels of the hierarchy. In particular, the epistemological ideal of science is the truth, and the normative structure of scientific activity as the search for that truth is still best described by the imperatives enunciated by Robert Merton in 1940s. Still, the most urgent of those imperatives is the one of universalism that subordinates any particular interests of social groups or communities to the universal ideal of the truth. Human dimension of post-non-classical science could be well described as the orientation on human personality as the subject of recognition of values, by mastering all values pre-given by culture and history of the humankind instead of alienating that process in favor of that or other social party.

According to the idea expressed in this paper, the main problem of the present-day situation in science is not so the threat of quasi-classical authoritarian or even totalitarian monism of the single truth that could appear as a result of considering the unifying universal value to constitute the highest hierarchical level, but on the contrary - the loss of the ability to perceive the ideals. Thus, the crisis of science in particular and the crisis of culture in general, resulting in conflicts all around the world, could be described as a result of the substitution of the universal and common ideal with means belonging to lower hierarchical levels that define the radical plurality and difference. Science in such situation is locked in a circulus vitiosus of sustaining its own functionality as a social system, engaged in reproducing the habits of a scientific community instead of pursuing its search for the truth. Only by revealing the universal ideal that does not hinder the plurality but enables the difference and the very possibility of discussions, there could be relevant and comprehending system of values investigated in relation to the present-day science - that would in turn enable us to solve the problem of the 
correlation between science aimed at objectivity and human cultural values. And it is problems and perspectives of human cultural (external) values and their impact on scientific knowledge that could present the subject for further investigations within the scope of the proposed topic.

\section{References}

Abisheva, A. K. (2002). On the notion of 'value'. The Questions of Philosophy (In Russian), 3, 139-146.

Bakhov, I. S. (2013). Government multicultural policy in Canada in the period of 1970-2000-s. Middle East Journal of Scientific Research, 15(10), 1450-1454. http://dx.doi.org/10.5829/idosi.mejsr.2013.15.10.11611

Bakhov, I. S. (2014). Dialogue of cultures in multicultural education. World Applied Sciences Journal, 29(1), 106-109. http://dx.doi.org/10.5829/idosi.wasj.2014.29.01.13775

Boychenko, M. I. (2011). System approach in social cognition: Axiological and functional aspects. Kyiv: Promin ' (In Ukrainian).

Branskiy, V. P. (2012). Philosophical analysis of the notion of value. In V. P. Branskiy, \& S. D. Pozharskiy (Eds.), Synergetic theory of values (In Russian, pp. 27-59).

Daston, L., \& Galison, P. (2010). Objectivity. New York: Zone Books.

Dobronravova, I. S. (2009). Post-non-classical rationality and philosophical foundations of synergetic methodology. In L. P. Kiyashchenko, \& V. S. Stepin (Eds.), Post-non-classics: Philosophy, science, culture (pp. 296-314).

Edel, A. (1963). Method in ethical theory. London: Routledge \& Kegan Paul.

Kopnin, P. V. (1973). Dialectics as logic and theory of knowledge: Essay on logical-epistemological investigation. Moscow: Nauka (In Russian).

Krymskiy, S. B. (2012). Sergey Krymskiy: Our life-long conversation (a series of interviews by T. A. Chayka). Kiev: Dmitriy Burago publishing house.

Longino, H. (2004). How values can be good for science. In P. Machamer, \& G. Wolters (Eds.), Science, values, and objectivity (pp. 127-142).

Merton, R. K. (1938/1973). The normative structure of science. In R. K. Merton (Ed.), The sociology of science. Theoretical and empirical investigations (pp. 267-278).

Mielkov, I. (2013). Human-commensurable systems: From complexity to harmony. Systems. Connecting matter, life, culture and technology, 1(1), 79-94.

Mielkov, I. (2014). Human-dimensionality of post-non-classical science. Kiev: Parapan (In Russian).

Mirskaya, Y. Z. (2008). Ethos of science: Ideal regulatives and everyday realities. In L. P. Kiyashchenko, \& Y. Z. Mirskaya (Eds.), Ethos of science. Moscow: Academia (In Russian).

Nasar, S., \& Gruber, D. (2006). Manifold destiny: A legendary problem and the battle over who solved it. The New Yorker, 28, 44-57.

Ortega y Gasset, H. (2007). La deshumanización del arte y otros ensayos de estética. Madrid: Espasa Calpe.

Putnam, H. (2002). The collapse of the fact/value dichotomy and other essays. London: Harvard University Press.

Putnam, H. (2005). Ethics without ontology. Harvard University Press.

Rescher, N. (1997). Objectivity: The obligations of impersonal reason. The University of Notre Dame Press.

Rescher, N. (2004). Value matters: Studies in axiology. Heusenstamm: Ontos Verlag. http://dx.doi.org/10.1515/9783110327755

Shinkaruk, V. I. (2003). Selected works (Vol. 3, No. 2). Kyiv: Ukrainian Center for Spiritual Culture (In Ukrainian).

Stepin, V. S. (2011). Civilization and culture. St.-Petersburg University Press (In Russian).

Stepin, V. S. (2005). Theoretical knowledge. Dordrecht: Springer. http://dx.doi.org/10.1007/1-4020-3046-0

Wilson, E. O. (1993). Biophilia and the conservation ethics. In S. R. Kellert, \& E. O. Wilson (Eds.), The biophilia hypothesis. Washington, D.C.: Island Press.

Yatsenko, A. I. (1977). Goal-setting and the ideals. Kiev: Naukova Dumka (In Russian). 
Zahorodniuk, V. P. (1991). Goal-setting in practice, culture, cognition. Kiev: Naukova Dumka (In Russian).

\section{Copyrights}

Copyright for this article is retained by the author(s), with first publication rights granted to the journal.

This is an open-access article distributed under the terms and conditions of the Creative Commons Attribution license (http://creativecommons.org/licenses/by/3.0/). 